\title{
Highly selective fluoride sensing via chromogenic aggregation of a silyloxy-functionalized tetraphenylethylene (TPE) derivative
}

\author{
Ilke Simsek Turan ${ }^{\mathrm{a}}$, Fatma Pir Cakmak ${ }^{\mathrm{b}}$, Fazli Sozmen ${ }^{\mathrm{a}, *}$ \\ ${ }^{a}$ UNAM-National Nanotechnology Research Center, Bilkent University, Ankara 06800, Turkey \\ ${ }^{\mathrm{b}}$ Department of Chemistry, Bilkent University, Ankara 06800, Turkey
}

\section{A R T I C L E I N F O}

\section{Article history:}

Received 25 July 2013

Revised 24 October 2013

Accepted 14 November 2013

Available online 23 November 2013

\begin{abstract}
A B S T R A C T
A silyloxy-functionalized tetraphenylethylene (TPE) derivative shows a remarkable change in the absorption spectrum on deprotection with fluoride ions. The reaction process is highly selective for fluoride and the resulting charge transfer band results in a bright green solution. A simple selective visual assay of aqueous fluoride ions was also obtained by the impregnation of cellulose strips with the TPE derivative.
\end{abstract}

(c) 2013 Elsevier Ltd. All rights reserved.

Keywords:

Fluoride sensing

TPE

Chromogenic aggregation

Fluoride ions

Selectivity

Tetraphenylethylene (TPE) and its derivatives have attracted remarkable attention due to their well-known aggregation-induced emission (AIE) $)^{1}$ properties, which make this small molecule an indispensible building block in several areas such as OLEDs, chemosensors, and bioprobes. ${ }^{2}$ The outstanding electrochemical, physical, and excited state properties, especially in the solid state, are a result of the extended $\pi$-system found in TPE. ${ }^{3}$

Fluoride ion sensing is an important topic because of the biological significance of this anion, especially in relation to dental care, and in the treatment of osteoporosis. ${ }^{4}$ However, fluoride ion sensing is a highly challenging task due to the high electronegativity of fluorine, its strong hydrogen bonding ability and its size (smallest anion).

In addition, real time monitoring of fluoride ions is extremely difficult in aqueous media, especially via chromogenic chemosensors due to competitive hydrogen bonding between fluoride and water molecules. ${ }^{5}$ A reaction-based sensor could have some advantages considering the simplicity of the analytical procedure. In this respect, naked eye anion detection with chemosensors capable of detecting anions is becoming increasingly important for rapid on-site analysis, on a real time basis. Current chromogenic anion sensors typically have hydrogen bonding receptor sites, some with selectivity for fluoride, but are less likely to work in aqueous medium. ${ }^{6}$

\footnotetext{
* Corresponding author. Tel.: +90 312290 3568; fax: +90 3122664068 .

E-mail address: sozmen@unam.bilkent.edu.tr (F. Sozmen).
}

The high chemical affinity between fluoride and silicon has been widely used in previous studies to sense fluoride anions, however, there are only a few which work in aqueous solutions. ${ }^{7}$

Herein, we report the design and synthesis of a highly selective and sensitive chromogenic fluoride anion sensor, TPE $\mathbf{5}$. The synthesis of target compound $\mathbf{5}$ started with the reaction between 4methoxyphenyllithium (from 1-bromo-4-methoxybenzene and butyllithium) and 4-methoxybenzaldehyde to produce alcohol 1, which was oxidized to compound 2 using manganese(IV) oxide in dichloromethane. Compound $\mathbf{3}$ was then obtained through a McMurry coupling of compound $\mathbf{2}$. This was followed by demethylation to give $\mathbf{4}$. Further reaction of compound $\mathbf{4}$ with chlorotriisopropylsilane in the presence of imidazole yielded the target fluoride anion sensor $\mathbf{5}$ (Scheme 1).

Fluoride sensing of TPE $\mathbf{5}$ was accomplished by deprotection of the silyl groups from the TPE core generating four phenoxide ions in full conjugation with the TPE moiety, which leads to very strong intramolecular charge transfer (ICT). ${ }^{8}$

This strong ICT resulted not only in the formation of new charge transfer bands in the absorbance spectrum corresponding to a bright green solution, but also led to quenching of the emission in the fluorescence spectrum.

In the electronic absorption spectrum, a maximum was observed at $340 \mathrm{~nm}$ for compound $\mathbf{5}$ in DMF. Next, the solution of compound 5 ( $50 \mu \mathrm{M}$ in DMF) was treated with fluoride ions in the form of a tetrabutylammonium salt (TBAF). The absorption spectra during titration showed new bands appearing at 452 , 510,600 and $680 \mathrm{~nm}$, respectively. The band at $600 \mathrm{~nm}$ was the 


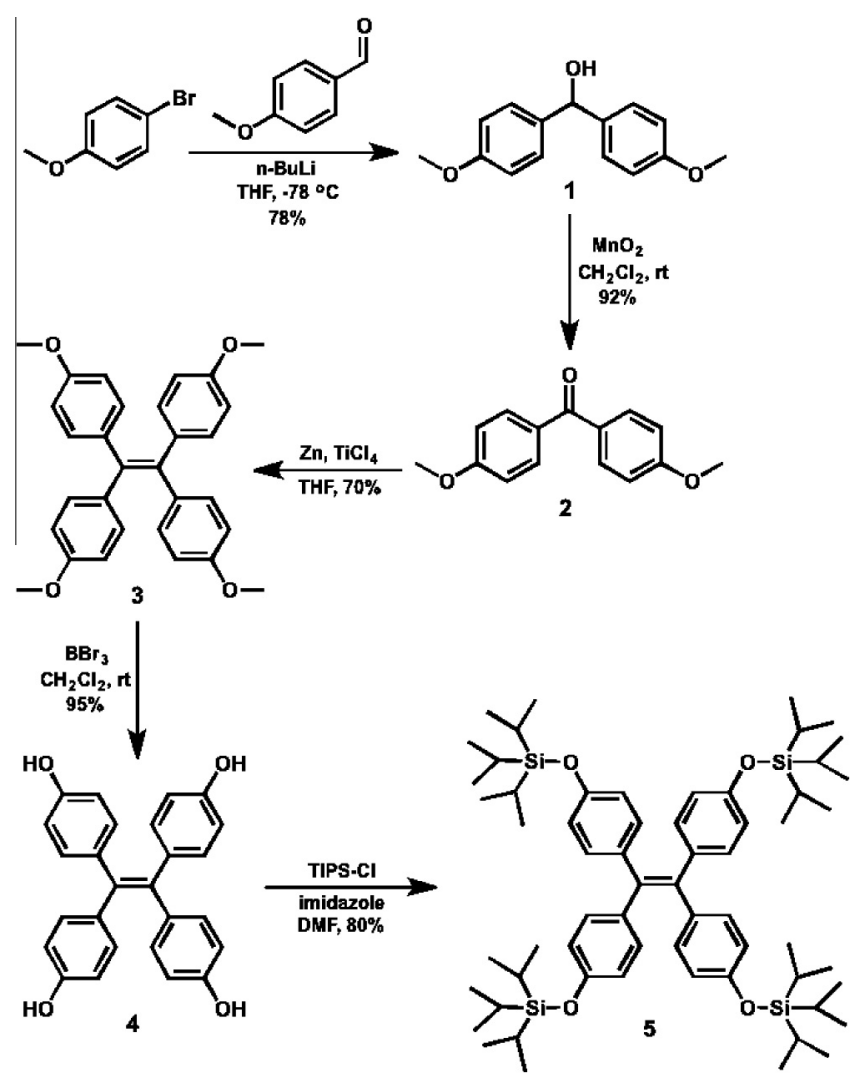

Scheme 1. Synthesis of fluoride sensor 5.

most intense, resulting in a bright green color of the solution (Fig. 1).

The electronic absorption spectra of $\mathbf{5}$ were also investigated upon the addition of eight equivalents of the TBA salts of $\mathrm{HSO}_{4}^{-}$, $\mathrm{H}_{2} \mathrm{PO}_{4}^{-}, \mathrm{AcO}^{-}, \mathrm{NO}_{3}^{-}, \mathrm{CN}^{-}, \mathrm{I}^{-}, \mathrm{Br}^{-}$, and $\mathrm{Cl}^{-}$to DMF solutions of $\mathbf{5}$. The addition of these anions did not result in any changes in the absorption spectrum (Fig. S1), or the emission spectrum.

Figure 2 (bottom) shows the color change after the addition of eight equivalents of the anions as TBA salts to the DMF solution

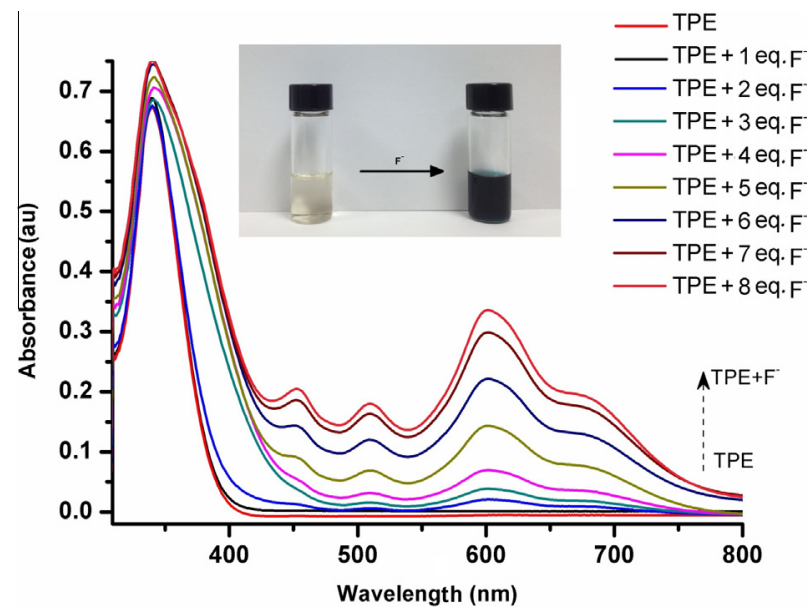

Figure 1. Absorbance spectra of compound $\mathbf{5}+\mathrm{F}^{-}$in the presence of increasing $\mathrm{F}^{-}$ concentrations. The inset is a digital photograph of the probe (left) and probe following the addition of 8 equivalents of $\mathrm{F}^{-}$(right). Probe concentration is $50 \mu \mathrm{M}$ in DMF.
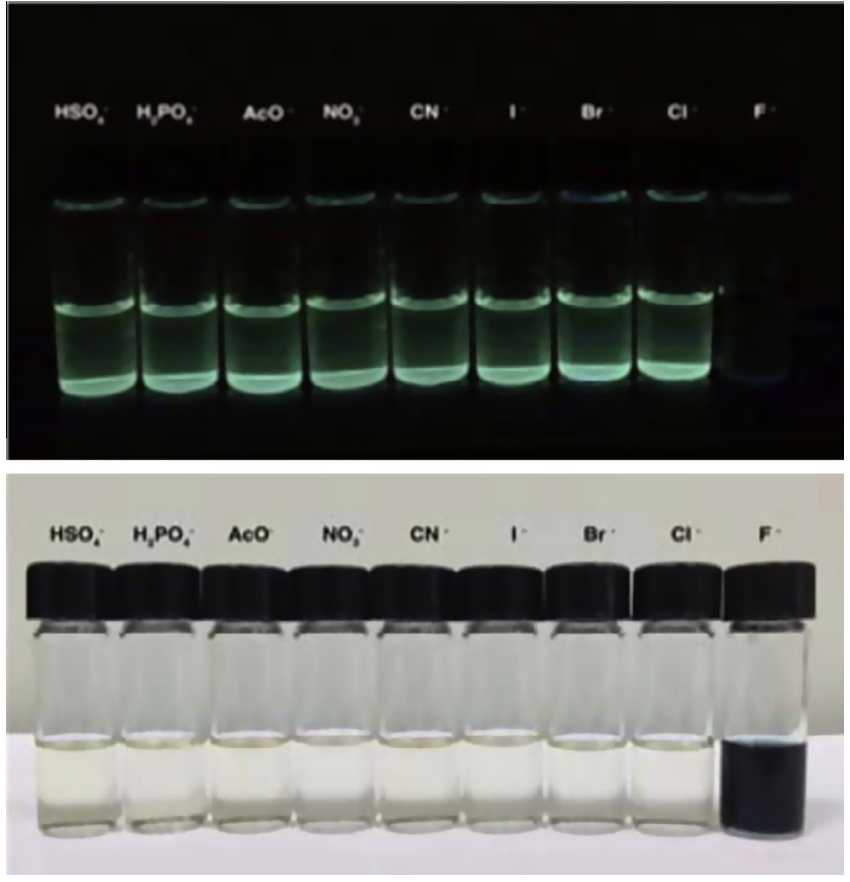

Figure 2. The digital photographs show the appearance of the solutions under a hand-held UV lamp (360 nm) (top) and under ambient light (bottom). Probe concentrations were $50 \mu \mathrm{M}$ and the anions were added at $0.4 \mathrm{mM}$ concentrations, all in DMF.

of 5. Clearly, no color change was observed upon addition of the other anions; only fluoride ions led to a color change.

The emission spectra of compound 5 (50 $\mu \mathrm{M}$ in DMF) showed drastic quenching upon addition of fluoride anions in the form of TBA salts (Fig. 3). The strong charge transfer character of the formed phenoxide moieties leads to this quenching. As expected, no emission quenching was observed upon addition of other ions as TBA salts as shown in Figure 4 (top). The spectacular difference between fluoride anions and the other anions in terms of emission intensity is clearly shown in the bar graphs (Fig. 4, bottom). Furthermore, selective quenching of fluoride is shown in the digital photographs of DMF solutions under the indicated conditions (Fig. 2, top).

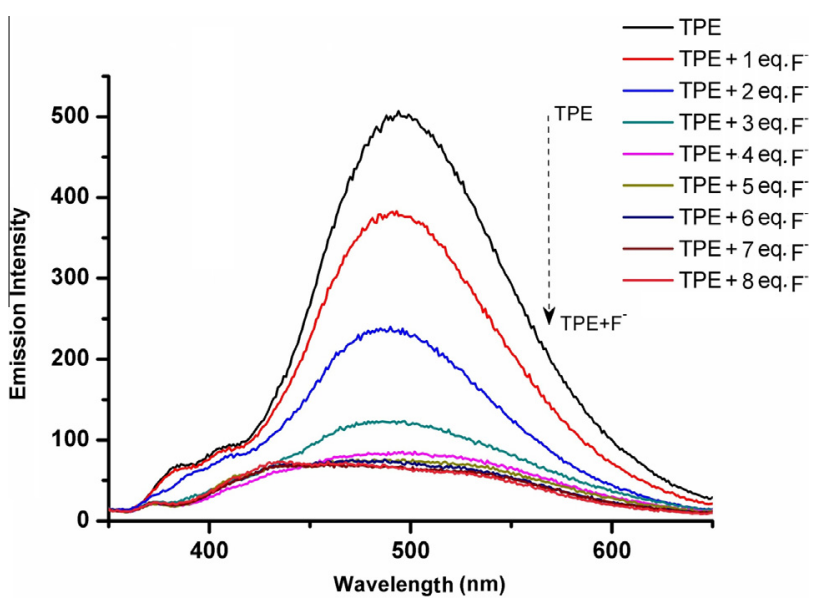

Figure 3. Emission spectra of compound $\mathbf{5}+\mathrm{F}^{-}$in the presence of increasing $\mathrm{F}^{-}$ concentrations. Probe concentration is $50 \mu \mathrm{M}$ in DMF. Excitation wavelength is $340 \mathrm{~nm}$. 

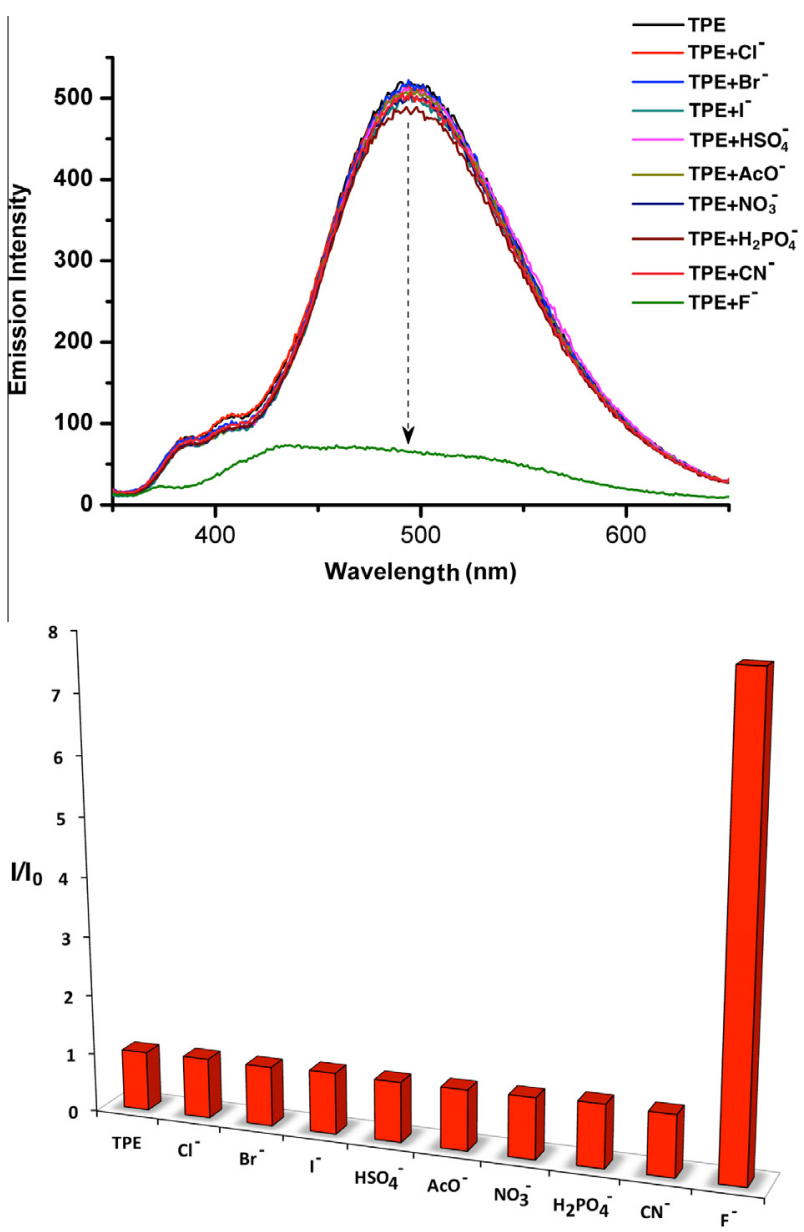

Figure 4. Emission spectra of compound $\mathbf{5}$ upon the addition of 8 equivalents of $\mathrm{Cl}^{-}, \mathrm{Br}^{-}, \mathrm{I}^{-}, \mathrm{HSO}_{4}^{-}, \mathrm{AcO}^{-}, \mathrm{NO}_{3}^{-}, \mathrm{H}_{2} \mathrm{PO}_{4}^{-}$, and $\mathrm{CN}^{-}$. The $\mathrm{F}^{-}$and probe concentrations are both $50 \mu \mathrm{M}$, all in DMF. The bar graph shows the emission ratios $\left(I / I_{0}\right)$

In order to explore whether compound $\mathbf{5}$ could respond to fluoride anions in solid state via chemical reactions, we decided to prepare a test paper for detecting fluoride in an aqueous environment by dipping a cellulose strip $\left(3.0 \times 0.5 \mathrm{~cm}^{2}\right)$ into a tetrahydrofuran solution of $\mathbf{5}(4.0 \mathrm{mM})$. After drying the cellulose strip under ambient conditions, it was immersed in an aqueous fluoride solution (water/tetrahydrofuran, 2:8) for several seconds followed by a short heat treatment.

The color of the cellulose strip was clearly and reproducibly changed from white to green (Fig. 5). However the color change was not uniform throughout the test strip. The underlying reason for this maybe that the sensing process was achieved by a chemical reaction taking place on the cellulose fibers, introducing some heterogeneity in the solid state.

In conclusion, we have reported a new chemical reaction based on a chromogenic fluoride anion probe operating via deprotection of the silyl groups from TPE derivative $\mathbf{5}$. The deprotection of four silyl groups results in four donor phenoxide groups causing strong intramolecular charge transfer. This strong ICT also induces considerable fluorescence quenching and the occurrence of new absorbance bands in the visible region resulting in a bright green solution. This highly selective sensing was also, demonstrated in aqueous environments using a stained cellulose strip. Thus, a naked-eye chromogenic chemosensor $\mathbf{5}$ has been described for detection of fluoride anions and this dye impregnated cellulose strip could be a prototype material for the easy and fast chemical detection of fluoride.

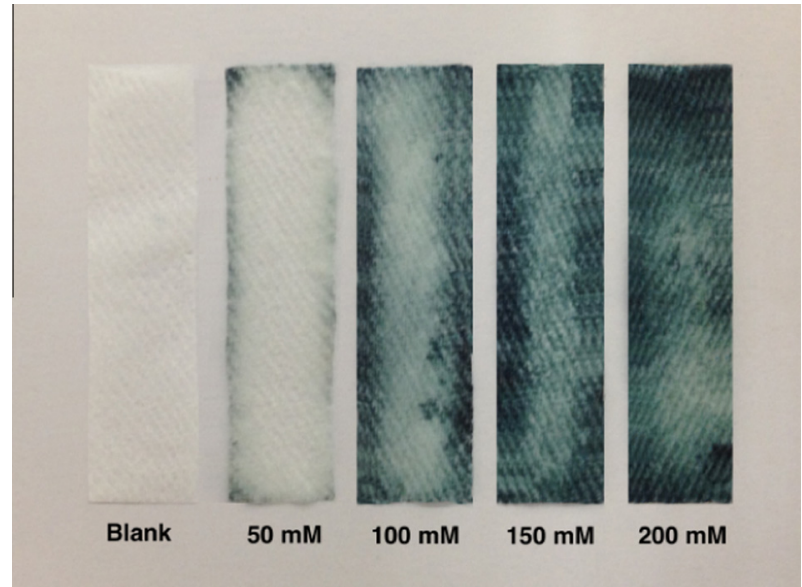

Figure 5. The color changes of the treated cellulose strips prepared for the detection of fluoride anions in aqueous environments, on exposure to different fluoride concentrations.

\section{Acknowledgment}

The authors thank Professor Dr. Engin U. Akkaya for fruitful discussions. I.S.T. acknowledges support from TUBITAK-BIDEB in the form of a scholarship.

\section{Supplementary data}

Supplementary data associated with this article can be found, in the online version, at http://dx.doi.org/10.1016/j.tetlet.2013 11.059 .

\section{References and notes}

1. (a) Luo, J.; Xie, Z.; Lam, J.; Cheng, L.; Chen, H.; Qiu, C.; Kwok, H. S.; Zhan, X.; Liu, Y.; Zhu, D.; Tang, B. Z. Chem. Commun. 2001, 1740-1741; (b) An, B. K.; Kwon, S. K.; Jung, S. D.; Park, S. Y. J. Am. Chem. Soc. 2002, 124, 14410-14415; (c) Chen, J.; Law, C. W.; Lam, J.; Dong, Y.; Lo, S.; Williams, I. D.; Zhu, D.; Tang, B. Z. Chem. Mater. 2003, 15, 1535-1546; (d) Tong, H.; Dong, Y.; Häußler, M.; Lam, J.; Sung, H. H.: Williams, I. D.; Tang, B. Z. Chem. Commun. 2006, 10, 1133-1135; (e) Yu, G. Yin, S. W.; Liu, Y. Q.; Chen, J. S.; Xu, X. J.; Sun, X. B.; Ma, D. G.; Zhan, X. W.; Peng, Q.; Shuai, Z. G.; Tang, B. Z.; Zhu, D. B.; Fang, W. H.; Luo, Y. J. Am. Chem. Soc. 2005 127, 6335-6346; (f) Lee, S. H.; Jang, B. B.; Kafafi, Z. H. J. Am. Chem. Soc. 2005, 127, 9071-9078.

2. (a) Dong, Y.; Lam, J. W. Y.; Qin, A.; Liu, J.; Li, Z.; Tang, B. Z.; Sun, J.; Kwok, H. S. Appl. Phys. Lett. 2007, 91, 011111; (b) Qin, A.; Lam, J. W. Y.; Tang, L.; Jim, C. K. W.; Zhao, H.; Sun, J.; Tang, B. Z. Macromolecules 2009, 42, 1421-1424; (c) Liu, L. Zhang, G.; Xiang, J.; Zhang, D.; Zhu, D. Org. Lett. 2008, 10, 4581-4584; (d) Hong, Y.; Haussler, M.; Lam, J. W. Y.; Li, Z.; Sin, K. K.; Dong, Y.; Tong, H.; Liu, J.; Qin, A.; Renneberg, R.; Tang, B. Z. Chem. Eur. J. 2008, 14, 6428-6437; (e) Peng, L.; Zhang, G.; Zhang, D.; Xiang, J.; Zhao, R.; Wang, Y.; Zhu, D. Org. Lett. 2009, 11, 40144017; (f) Kato, T.; Kawaguchi, A.; Nagata, K.; Hatanaka, K. Biochem. Biophys. Res. Commun. 2010, 394, 200-204; (g) Chen, Q.; Bian, N.; Cao, C.; Qiu, X.-L.; Qi, A.-D.; Han, B.-H. Chem. Commun. 2010, 46, 4067-4069; (h) Wang, J.-X.; Chen, Q.; Bian, N.; Yang, F.; Sun, J.; Qi, A.-D.; Yan, C.-G.; Han, B.-H. Org. Biomol. Chem. 2011, 9, 2219-2226.

3. (a) Wang, W: Lin, T.; Wang, M.; Liu, T.-X: Ren, L.; Chen, D.; Huang, S. J. Phys Chem. B. 2010, 114, 5983-5988; (b) Shih, P.-I.; Chuang, C.-Y.; Chien, C.-H.; Diau, E. W.-G.; Shu, C.-F. Adv. Funct. Mater. 2007, 17, 3141-3146; (c) Leung, C. W. T.; Hong, Y.; Chen, S.; Zhao, E.; Lam, J. W. Y.; Tang, B. Z. J. Am. Chem. Soc. 2013, 135 62-65.

4. (a) Farley, J. R.; Wergedal, J. E.; Baylink, D. J. Science 1983, 222, 330-332; (b) Kleerekoper, M. Endocrinol. Metab. Clin. North Am. 1998, 27, 441-452; (c) Yang, Z.; Zhang, K.: Gong, F.; Li, S.; Chen, J.: Ma, J. S.; Sobenina, L. N.; Mikhaleva, A. I.; Yang, G.; Trofimov, B. A. Beilstein J. Org. Chem. 2011, 7, 46-52; (d) Horowitz, H. S. J. Public Health Dent. 2003, 63, 3-8; Lennon, M. A. Bull. W.H.O. 2006, 84, 759-760.

5. (a) Harmon, K. M.; Gennick, I. Inorg. Chem. 1975, 14, 1840-1845; (b) Bao, Y.; Liu, B.; Wang, H.; Tian, J.; Bai, R. Chem. Commun. 2011, 47, 3957-3959; (c) Jiang, X.; Vieweger, M. C.; Bollinger, J. C.; Dragnea, B.; Lee, D. Org. Lett. 2007, 9, 35793582.

6. (a) Yong, X.; Su, M.; Wang, W.; Yan, Y.; Qu, J.; Liu, R. Org. Biomol. Chem. 2013, 11 2254-2257; (b) Bozdemir, O. A.; Sozmen, F.; Buyukcakir, O.; Guliyev, R.; Cakmak, Y.; Akkaya, E. U. Org. Lett. 2010, 12, 1400-1403; (c) Ke, B.; Chen, W.; Ni, 
N.; Cheng, Y.; Dai, C.; Dinh, H.; Wang, B. Chem. Commun. 2013, 49, 2494-2496; (d) Baker, M. S.; Phillips, S. T. Org. Biomol. Chem. 2012, 10, 3595-3599.

7. (a) Kim, S. Y.; Hong, J.-I. Org. Lett. 2007, 9, 3109-3112; (b) Sokkalingam, P.; Lee C.-H. J. Org. Chem. 2011, 76, 3820-3828; (c) Zheng, F.; Zeng, F.; Yu, C.; Hou, X.; Wu, S. Chem. Eur. J. 2013, 19, 936-942; (d) Kim, D.; Singha, S.; Wang, T.; Seo, E.; Lee, J. H.; Lee, S.-J.; Kim, K. H.; Anh, K. H. Chem. Commun. 2012, 48, $10243-$
10245; (e) Kim, S. Y.; Park, J.; Koh, M.; Park, S. B.; Hong, J.-I. Chem. Commun. 2009, 4735-4737.

8. (a) Atilgan, S.; Kutuk, I.; Ozdemir, T. Tetrahedron Lett. 2010, 51, 892-894; (b) Isik, M.; Ozdemir, T.; Turan, S. I.; Kolemen, S.; Akkaya, E. U. Org. Lett. 2013, 15, $216-$ 219; (c) Atilgan, S.; Ozdemir, T.; Akkaya, E. U. Org. Lett. 2010, 12, 4792-4795. 